\title{
Can Mathematics and Statistics Perception Explain Students' Statistical Literacy?
}

\author{
Risma Nurul Auliya \\ Universitas Indraprasta PGRI \\ Corresponding author: rismauliya@gmail.com
}

\begin{abstract}
The aim of this research is intended to examine the effect of mathematics and statistics perception towards students' statistical literacy. The research utilized a survey method with quantitative approach. The research population was undergraduate students from major informatics in one of university in Jakarta. The sample consisted of 80 students, 50 of students were male, while 30 of the students were female. All the participants belonged to similar grade level and enrolled in a statistics course. A survey instrument entitled "Mathematics and Statistics Perception Scale (MSPS)" was intended to examine undergraduate students' perceptions of self-efficacy and their attitudes toward the application of statistics in real world settings. The final version scale consists of 11 items. A multiplechoice survey with 22 questions measuring statistical literacy skills and consisted of items measuring skills on interpreting or critiquing the prevalence of statistical phrases and ideas in the media. The data collected were analyzed using linear regression and independent sample t-test. The result revealed that students' mathematics and statistics perception was found to be significantly and positively related to statistical literacy skills, while there is no significant differences between gender, perception, and statistical literacy. The linear regression analysis estimates the linear regression function to be $y=3.706+0.439 x$.
\end{abstract}

Keywords: Mathematics and statistics perception, statistical literacy, gender

\section{Introduction}

Statistics is a part of life in today's modern society. Statistical literacy has been recognized as essential knowledge that all citizens need to possess in today's informationdriven society (Yotongyos, Traiwichitkhun, and Kaemkate, 2015). Hand (Arumugam, 2014) stated that statistics is about solving real world problems. Statistics is not only needed for conducting scientific research, but also for being informed citizen and for advancing in technology as society (Arumugam, 2014). A statistically literate citizen would be able to understand statistical information via radio, television, the World Wide Web, and so on, and be able to make responsible decisions based on information (Hovermill, Beaudrie, and Boschmans, 2014). Besides, Rumsey (Yotongyos, Traiwichitkhun, and Kaemkate, 2015) added that being statistically literate enables one to consume and critically digest the wealth information being produced in society. In other words, statistics is an important tool for any individual who adapt him/herself to the changing world in which numerical data are increasing presented (Ben-Zvi and Garfield, in Arumugam, 2014).

Statistics courses were one of compulsory subject for university students (Arumugam, 2014). Schau et al. (Ncube and Moroke, 2015) stated most of students at undergraduate university level take statistics course as prerequisite for their degree 
programs. Frankenstein proposed that school plays a crucial role for improving students' statistical literacy ability, a literate student would be able to understand why and how statistics are useful in perceiving and interpreting the world and its complexity (Nikiforidou, Lekka, Pange, 2010). Schield (Yotongyos, Traiwichitkhun, and Kaemkate, 2015) described statistical literacy as the ability to interpret and evaluate statistics data, and the ability to use statistics as evidence in arguments. The competencies of statistical literacy can be viewed as an ability to understand basic statistical terms, such as percentage and average, to more advanced statistical methods and analysis (Peter, USC, Kellam, 2013). Statistical literacy concerns understanding statistics in their context; what they are telling us or what they are not. In this way, it is not about calculations that seemingly dominate much of statistics education in the schools, such as making graphs, finding measures of central tendency, calculating standard deviations and so on, but it is about understanding what these measures tell us in the context of the situation (Hovermill, Beaudrie, and Boschmans, 2014).

In order to succeed and use statistics, Schau suggested that students should think that statistics is valuable in their lives and realize that it is relevant to their academic and professional endeavors (Mandap 2016). It is important for students to like statistics, believe that they can understand and use statistics, and think that statistics is not too difficult to learn, so they would be willing to invest the effort needed to learn statistics (Arumugam: 2014; Emmioglu and Capa-Aydin, 2012). In other words, Schau stated that it is important for students to have positive attitudes towards statistics (Emmioglu and Capa-Aydin, 2012). Ramirez stated that positive attitudes towards statistics can keep students using what they have learned and encourage them to seek opportunities to learn more (Sesé, Jiménez, Montaño, Palmer: 2015).

Unfortunetelly, statistics classes seem universally disliked by college students and have become barriers for their graduation (Hogg, Onwuegbuzie; Schau, Millar, and Petocz, in Hedges and Harkness, 2017). Usually, before entering university level, students have wrong perceptions and misapprehensions about statistical ideas (Chadjipadelis and Gastaris; Garfield, in Nikiforidou, Lekka, Pange, 2010). Students often consider statistics as a difficult subject to learn and associated with students' negative feelings towards statistics. Statistics viewed as one of the biggest hurdles they face in their study (Arumugam, 2014). According to Chiesi and Primi (Sesé, Jiménez, Montaño, Palmer: 2015), some students could consider statistics as a burden because they are not have selfconfident about their statistics competences (Mandap, 2016) and they do not like or not good in mathematics (Hedges and Harkness, 2017). Students thought that the most statistical concepts are complex and difficult to understand (Mandap, 2016), and they were used to memorize statistical knowledge and follow rules and procedures in standard contexts (Vanhoof, in Arumugam, 2014). Galli et al. (Ncube and Moroke, 2015) highlighted that a poor performance in statistics was often preceded by negative perception. It can be clearly seen that one's perception of their capability, their expectations of success in course, their valuing of an activity may impact on their persistence and motivation to learn, and in advance lead to their academic performance (Gutman and Schoon, in Ncube and Moroke, 2015).

In this study the term "perception in mathematics and statistics" refers to somekind of mental representation or view of mathematics and statistics, originated from past experience as well as associated beliefs, attitudes, and conceptions (Mutodi, 2014). Many students believed "learning mathematics or statistics is a question more of ability than effort" (McLeod, in Mutodi and Ngirande, 2014). They hold the view that learning mathematics and statistics are only for the clever ones, or only for those who have "inherited mathematical/statistical ability" (Mutodi and Ngirande, 2014). Personal beliefs 
and perception of their capability affect the students' interest in learning, efficiency in performing tasks, motivation and pleasure, attribution of causes to academic success or failure, and self-concept (Mutodi and Ngirande, 2014).

Most students go to university with different experiences and background in statistics as this subject not fully taught in high school. Besides, Chiesi and Primi (Ncube and Moroke, 2015) explained that students enter introductory classes with different levels of competences, especially mathematics competence, and then their statistical reasoning and numeracy skills are constantly tested and challenge in statistics class. Usually, students who do not have the background knowledge in mathematics were often feeling nervous about taking any statistics course. In order to assess the effect of mathematics and statistics perception towards statistical literacy among undergraduate students, the following research question was addressed in this study: is there an effect of mathematics and statistics perception towards statistical literacy? In addition, this study was conducted to determine the differences between gender, perception, and statistical literacy.

\section{Research Methods}

The research utilized a survey method with quantitative approach. Survey research is a commonly used method of collecting information about a population of interest. A subgroup of the population was selected to answer the survey questions, then the information collected can be generalized to the entire population of interest

The population of this research was undergraduate students from major informatics in one of university in Jakarta. The sample consisted of 80 students, 50 of students were male, while 30 of the students were female, who were selected using purposive random sampling. All the participants belonged to similar grade level and enrolled in a statistics course. The participation was voluntary and the students were told that their responses to the survey would not affect their grades.

Data obtained from the results of statistical literacy test and questionnaires carried out by students. A multiple-choice survey with 22 questions measuring statistical literacy skills was adapted from Schield (2008). The survey consisted of items measuring skills on interpreting or critiquing the prevalence of statistical phrases and ideas in the media. Of the 22 multiple-choice questions, 8 were true false. A higher score means a higher level of skills in statistical literacy.

Besides, students completed a survey instrument entitled "Mathematics and Statistics Perception Scale (MSPS)" (Cherney and Cooney, 2005: 8) that was intended to examine undergraduate students' perceptions of self-efficacy and their attitudes toward the application of statistics in real world settings. The initial scale consisted of 15 items and the final version consists of 11 items. The statements were anchored using a 4-point Likert-type rating $(1=$ strongly disagree, $2=$ disagree, $3=$ agree, $4=$ strongly agree). No neutral point was included in order to get the respondents to voice an opinion. Negatively worded items were later reverse coded. A reliability analysis of the survey instrument gives a high value with a Cronbach alpha of 0.704 for all items. A mean score was employed to conclude the respondents' feedbacks towards each perception item given in the survey form. A high score shows a high positive perception.

Both sets of tests were run on an SPSS package, using significance level 0.05. The data analyzed by linear regression analysis to examined that there is an effect of mathematics and statistics perception towards statistical literacy, and how far mathematics and statistics perception explained students' statistical literacy. The data that collected from questionnaire and test results, proceed through these stages: (1) Give scoring for students' answer refer to answer key and guidelines scoring; (2) Statistics assumption trial, means normality, linearity, heteroscedasticity, and autocorrelation test; (3) Linear regression analysis. 


\section{Results and Discussion}

Descriptive Statistics of Perception and Statistical Literacy

According to the result obtained, the mean, standard deviation, minimum and maximum of perception and statistical literacy are as table below. It is recorded in Table 1, with regards to mathematics and statistics perception, that the mean score of perception and literacy female and male students were not much different, there are 22.40 for female and 21.68 for male for perception, and 13.90 (female) and 13.00 (male) for literacy. Female students had higher standard deviation of perception and literacy than male. It showed that female students' perception and literacy were more variated than male. Score minimum for female was higher than male, around 2 point for perception and 4 point for literacy. While, score maximum of perception and literacy for both were same.

Table 1. Descriptive Statistics of Perception and Statistical Literacy

\begin{tabular}{lccccc}
\hline & $N$ & Minimum & Maximum & Mean & Std. Deviation \\
\hline literacy_female & 30 & 9 & 19 & 13.90 & 3.044 \\
literacy_male & 50 & 7 & 19 & 13.00 & 2.871 \\
perception_female & 30 & 13 & 36 & 22.40 & 6.223 \\
perception_male & 50 & 9 & 36 & 21.68 & 5.923 \\
Valid N (listwise) & 30 & & & & \\
\hline
\end{tabular}

Independent samples t-test analysis was conducted on the data to compare perception and statistical literacy based on gender. The result in Table 2 indicated that there is not a difference in statistical literacy skills for female and male students $(t=1.327$ and $\mathrm{p}=0,188>0.05)$. When analyzing if gender differences was required and the mathematics and statistics perception scale, there was no statistically significant difference between gender $(t=0.516$ and $p=0.607>0.05)$. These are consistent with previous finding (Wismath and Worrall, 2015), there is no significant gender differences in attitude and mathematics ability. Gender was not a significant factor in the study though we had thought it might be given the volume of research devoted to gender issues in mathematics. Although, contrary with the findings of research by Taylor et al.; Leder et al.; Schiebinger (Wismath and Worrall, 2015), which explained that gender is an important factor in mathematics ability, performance, and motivation, with special attention to math anxiety.

\section{Analysis by Question of Literacy Test}

The percentage of students that got question right ranged from $30 \%$ to $94 \%$ as shown in Figure 1. Most of students failed to answered correctly questions number 1, 7, 11,20 , and 22, namely questions about graphs and charts, comparisons, and measures of central tendency. Teachers tend to focus on which questions students missed (Schield, 2008). This indicates materials that must be covered to help students improve their statistics literacy skills. 
Table 2. T-test for gender differences

\begin{tabular}{llccccc}
\hline & & \multicolumn{5}{c}{ t-test for Equality of Means } \\
\cline { 3 - 7 } & & & & Sig. (2- & Mean & Std. Error \\
tailed) & Difference & Difference \\
\hline \multirow{2}{*}{ literacy } & Equal variances assumed & 1.327 & 78 & .188 & .900 & .678 \\
& Equal variances not assumed & 1.308 & 58.384 & .196 & .900 & .688 \\
\hline \multirow{2}{*}{ perception } & Equal variances assumed & .516 & 78 & .607 & .720 & 1.394 \\
& Equal variances not assumed & .510 & 58.805 & .612 & .720 & 1.412 \\
\hline
\end{tabular}

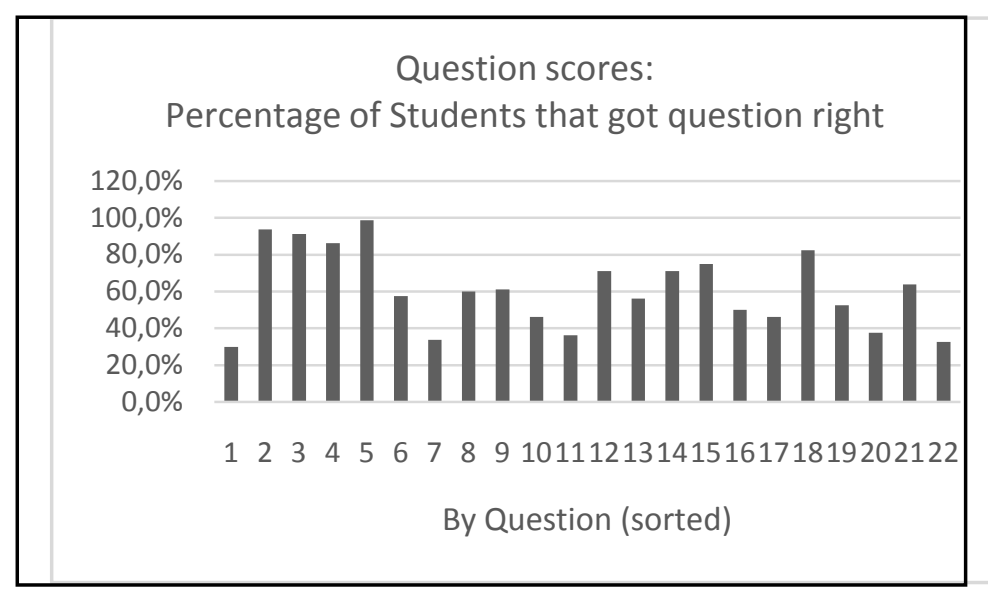

Figure 1. Question scores (ascending)

\section{Mean Scores for Mathematics and Statistics Perception}

Table 3 showed the mean score for each item perception component. The respondents have exhibited their agreement and disagreement towards the items in the component. They have shown a positive perception towards statements like item a1, a2, a3, a4, a5, a7, a8, a9, a10 with a mean 1.96, 1.65, 1.56, 2.29, 1.63, 1.38, 1.80, 2.33, and 2.75. A negative perception was displayed for statements a6 (mean $=2.28$ ) and a11 $($ mean $=2.34)$ respectively. Students were found to show a positive attitude and assumed that they need statistics and mathematics in everyday life, even though some of them thought that studying mathematics was not important.

Table 3. Mean Scores for Mathematics and Statistics Perception

\begin{tabular}{clc}
\hline Item & \multicolumn{1}{c}{ Perception } & Mean \\
\hline a1 & I am confident in my mathematics skills & 1.96 \\
\hline a2 & I enjoy doing calculations & 1.65 \\
\hline a3 & I like using mathematical formula & 1.56 \\
\hline a4 & I understand why we need mathematics in everyday life & 2.29 \\
\hline a5 & I like college mathematics class & 1.63 \\
\hline a6 & Mathematics is my least favorite subject & 2.28 \\
\hline a7 & I have always loved mathematics & 1.38 \\
\hline a8 & Mathematics comes easy to me & 1.80 \\
\hline a9 & I expect to do well in a statistics course & 2.33 \\
\hline a10 & Statistics is a useful skill in everyday life & 2.75 \\
\hline a11 & Studying mathematics is a waste of time & 2.34 \\
\hline
\end{tabular}




\section{Regression Linear Analysis}

The linear regression analysis was conducted in order to examine the effect of mathematics and statistics perception towards statistical literacy. Previously, the assumptions of regression must be fulfilled, such as normality, linearity, autocorrelation, and homoscedasticity.

Table 4. F-test

\section{ANOVA $^{\mathrm{b}}$}

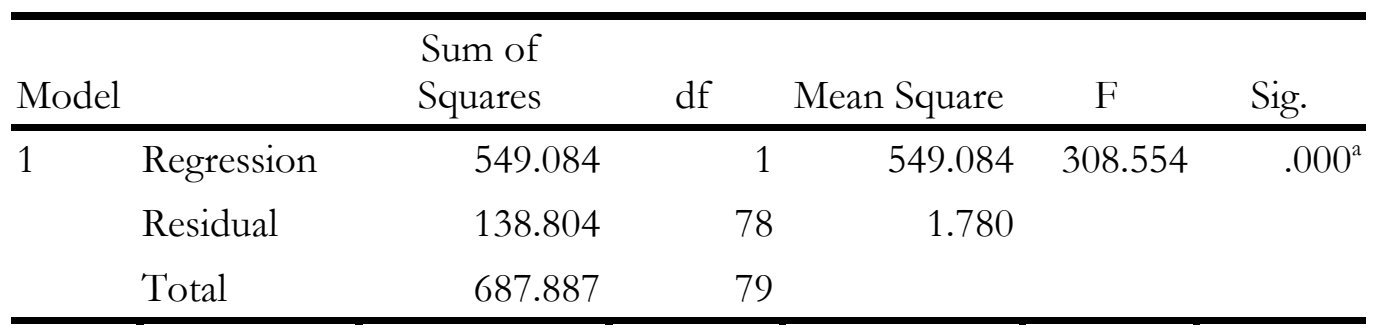

a. Predictors: (Constant), Perception

b. Dependent Variable: Literacy

Table 4 showed that the linear regression's F-test has the null hypothesis that there is no linear relationship between two variables (mathematics and statistics perception and statistical literacy). With significant value $=0.000$ and 50 degrees of freedom, the test is highly significant, thus we can assume that there is a linear relationship between the variables in regression model, or it can be said that mathematics and statistics perception variable have a statistically significant effect on statistical literacy skills.

In line with the findings of study conducted by Wasike, Michael, Joseph (2013), which indicated that there were significant differences in the students' performance and perception towards Mathematics. Students with negative perception towards mathematics were not performing well as their counterparts with positive attitudes. This tends to suggest that students' performance will largely be shaped by their perception, because the perception creates an impetus into the student's mind which creates a culture to like or dislike the subject. When these students' perceptions are not strengthened towards an undertaking, they often don't do quite well academically, even though they have the ability to do well under conducive environment

Table 5. Linear Regression Analysis

\begin{tabular}{|c|c|c|c|c|c|c|}
\hline \multirow{2}{*}{\multicolumn{2}{|c|}{ Model }} & \multicolumn{2}{|c|}{$\begin{array}{c}\text { Unstandardized } \\
\text { Coefficients }\end{array}$} & \multirow{2}{*}{$\begin{array}{c}\begin{array}{c}\text { Standardized } \\
\text { Coefficients }\end{array} \\
\text { Beta }\end{array}$} & \multirow[b]{2}{*}{$\mathrm{t}$} & \multirow[b]{2}{*}{ Sig. } \\
\hline & & B & Std. Error & & & \\
\hline \multirow[t]{2}{*}{1} & (Constant) & 3.706 & .568 & & 6.522 & .000 \\
\hline & Perception & .439 & .025 & .893 & 17.566 & .000 \\
\hline
\end{tabular}

a. Dependent Variable: Literacy

In Table 5, we found that the linear regression analysis estimates the linear regression function to be $y=3.706+0.439 x$, where $x$ represents mathematics and statistics perception and $y$ represents statistical literacy. Furthermore, it shows that for every 1 additional mathematics and statistics perception, we would expect to see 0.439 additional statistical literacy skills. Also, we found that a positive effect of mathematics and statistics perception and students' statistical literacy. Table 6 represented that the 
coefficient of determination is 0.798 ; therefore, about $79.8 \%$ of the variation in the statistical literacy data is explained by mathematics and statistics perception.

Table 6. Coefficient of determination

\begin{tabular}{lrrrr}
\hline Model & R & R Square & $\begin{array}{c}\text { Adjusted R } \\
\text { Square }\end{array}$ & $\begin{array}{l}\text { Std. Error of } \\
\text { the Estimate }\end{array}$ \\
\hline 1 & $.893^{\mathrm{a}}$ & .798 & .796 & 1.334 \\
\hline a. Predictors: (Constant), Perception & & &
\end{tabular}

The results of the study provide initial evidence that the mathematics and statistics perception have an effect on students' statistical literacy. In line with the results of research conducted by Cherney and Cooney (Mandap, 2016), which stated that mathematics and statistics perception are part of statistics anxiety components. Similarly, Aiken, Auzmendi, Olson and Zanna, Gómez Chacón stated that self-perception is one of components of the term 'attitude', which included perception of self-competence, knowledge, and intellectual skills when applied to statistics (Estrada, Batanero, and Lancaster, 2011).

Hood (Sesé, Jiménez, Montaño, Palmer: 2015) found that attitudes toward statistics could be considered as important factor for improving statistics performance, which may influence statistical literacy (Galli, Ciancaleoni, Chiesi, and Primi, in Martinez-dawson, 2010). Wise, Gal, and Zeidner (Martinez-dawson, 2010) found that positive attitudes promote better appreciation and influence students' willingness to take statistics course. In contrast, Shaughnessy, Gal, Ginsburg, and Schau (Martinez-dawson, 2010) indicated that poor attitudes towards statistics contribute to difficulties in learning statistics concepts hinder the development of statistical thinking skills.

Statistics educators can be better address the extent and effectiveness of their teaching methods to improve students' learning of statistics by understanding students' perceptions of their mathematics and statistics experiences (Hedges and Harkness, 2017). Besides, learning with integrating of computers and use statistical software, using practical examples and using real life data could be instrumental in sparking students' interest as they discover the relevance of statistics in their lives (Ncube and Moroke, 2015).

Future studies should continue to explore the relationship between undergraduate students' perceptions toward statistics and statistical literacy. This study was limited in the fact that the sample was biased. There were only 80 total subjects and these subjects were only those students willing to participate in the study. These students could have not answered the questions honestly due to possessing knowledge of the research process or only completing the survey to gain credit. Those only completing the survey to gain credit in the course may not have answered accurately due to their disinterest in participating. There were also several participants who did not complete the entre survey, which left incomplete responses to the different scales. These specific results may not have occurred if there was a different, more varied sample of undergraduate students. Future research should aim gain a more diverse sample of college majors. Those students in a major that rely heavily on statistics could skew the results. These topics have not been thoroughly researched and this study only provides a brief insight to the relationship between these two aspects (perception and statistical literacy). Hopefully college educators of statistics are able to use this knowledge to better understand their 
student. This could lead students to leave their statistics course feeling more positively about statistics as a whole.

\section{Conclusion}

This study investigates the effect of mathematics and statistics perception towards statistical literacy shared by undergraduate students from major informatics. Result from regression analysis revealed that students' mathematics and statistics perception was found to be significantly and positively related to statistical literacy skills. The linear regression function to be $y=3.706+0.439 x$, where $x$ represents mathematics and statistics perception and $y$ represents statistical literacy, and about $79.8 \%$ of the variation in the statistical literacy data is explained by mathematics and statistics perception.

Generally, mathematics and statistics perception have an influence in the way students' statistical literacy skills. In addition, the research findings also showed that no significant differences between gender, perception, and statistical literacy. Results from this study can provide the foundation for other studies to optimize factors, such as teaching method in order to help develop students' statistical literacy.

\section{Bibliography}

Arumugam, R. N. (2014). Students' Attitude toward Introductory Statistics Course at Public Universities using Partial Least Square Analysis. Interdisciplinary Journal of Contemporary Research in Business, 6(4), pp. 94-123. Available online: http://euabr.com/ijcrbaug14/94-123aug14.pdf.

Cherney, I. D., Cooney, R. R. (2005). Predicting Student Performance in a Statistics Course using the Mathematics and Statistics Perception Scale (MPSP). Transactions of the Nebraska Academy of Science and Affiliated Societies, 30, pp. 1-8. Available online: https://digitalcommons.unl.edu/cgi/viewcontent.cgi?article $=1040 \& \operatorname{context}=\mathrm{t}$ nas.

Emmioglu, E., Capa-Aydin, Y. (2012). Attitudes and Achievement Statistics: A MetaAnalysis Study. Statistics Education Research Journal, 11(2), 95-102.

Estrada, A., Batanero, C., Lancaster, S. (2011). Teachers' Attitudes Towards Statistics. Teaching Statistics in School-Mathematics-Challenges for Teaching and Teacher Education: A Joint ICMI/LASE Study, C. Batanero, G. Burrill, \& C. Reading (Eds.), pp. 163- $174 . \quad$ Available online: http://www.ugr.es/ batanero/pages/ARTICULOS/Chap_Estrada.pdf.

Hedges, S., Harkness, S. S. (2017). Is Gaise Evident? College Students' Perceptions of Statistics Classes as "Almost not Math". Statistics Education Research Journal, 16(1), pp. 337-356. Available online: https://iaseweb.org/documents/SERJ/SERJ16(1)_Hedges2.pdf.

Hovermill, J., Beaudrie, B., Boschmans, B. (2014). Statistical Literacy Requirements for Teachers. Proceedings of the Ninth International Conference on Teaching Statistics (ICOTS9), pp. 1-6. Available online: https://iaseweb.org/icots/9/proceedings/pdfs/ICOTS9_7B1_BEAUDRIE.pdf.

Mandap, C. M. (2016). Examining Gender Differences in Statistics Anxiety among College Students. International Journal of Education and Research, 4(6), pp. 357-366. Available online: http://www.ijern.com/journal/2016/June-2016/31.pdf.

Martinez-dawson, R. (2010). The Effects of A Course on Statistical Literacy upon Students' Challenges to Statistical Claims Made in The Media. Dissertation. Clemson University. Available online: 
https:/ / tigerprints.clemson.edu/cgi/viewcontent.cgi?article $=1616 \&$ context $=\mathrm{a}$ ll_dissertations.

Mutodi, P., Ngirande, H. (2014). The Influence of Students` Perceptions on Mathematics Performance. A Case of a Selected High School in South Africa. Mediterranean Journal of Social Sciences, 5(3), pp. 431-445. Available online: http://www.mcser.org/journal/index.php/mjss/article/download/2161/214 8.

Ncube, B., Moroke, N. D. (2015). Students' Perception and Attitudes towards Statistics in South African University: An Exploratory Factor Analysis Approach. Journal of Governance and Regulation, 4(3), pp. 231-240. Available online: https://repository.nwu.ac.za/bitstream/handle/10394/25999/2015Students_ perceptions.pdf?sequence $=1$.

Nikiforidou, Z., Lekka, A., Pange, J. (2010). Statistical Literacy at University Level: The Current Trends. Procedia Social and Behavioral Sciences, 9, pp. 795-799. Available online: $\quad$ https://ac.els-cdn.com/S1877042810023414/1-s2.0S1877042810023414-main.pdf?_tid=78bb074f-0933-42de-84081533edad4739\&acdnat $=1523506460 \_b b f 284457305 c 4 a a 2 f 2 e 470728 b 6 d c 08$.

Peter, K., USC., Kellam, L. (2013). Statistics and the Single Girl: Incorporating Statistical Literacy into Information Literacy Instruction. LOEX Quarterly, 40(1), pp. 210. Available online: https://libres.uncg.edu/ir/uncg/f/L_Kellam_Statistics_2013.pdf.

Schield, M. (2008). Statistical Literacy Skills Survey. W. M. Keck Statistical Literacy Project, pp. 1-19. Available online: https://www.researchgate.net/publication/262006747_Statistical_Literacy_Sk ills_Survey.

Sesé, A., Jiménez. R., Montaño, J. J., Palmer, A. (2015). Can Attitudes Toward Statistics and Statistics Anxiety Explain Students' Performance? Revista de Psicodidáctica, 20(2), pp. 285-304. Available online: http://repositori.uib.es/xmlui/bitstream/handle/11201/1706/546980.pdf?se quence $=1$ \&is Allowed $=\mathrm{y}$.

Wasike, A., Michael, N., Joseph, K. K. (2013). The Impact of Perception on Performance in Mathematics of Female Students in Secondary Schools in Teso District, Kenya. Journal of Education and Practice, 4(20), pp. 104-110.

Wismath, S. L., Worrall, A. (2015). Improving University Students/ Perception of Mathematics and Mathematics Ability. Numeracy, 8(1), pp. 1-17. Available online: http://scholarcommons.usf.edu/numeracy/vol8/iss1/art9

Yotongyos, M., Traiwichitkhun, D., Kaemkate, W. (2015). Undergraduate Students' Statistical Literacy: A Survey Study. Procedia Social and Behavioral Sciences, 191, pp. 2731-2734. Available online: https://ac.elscdn.com/S1877042815025884/1-s2.0-S1877042815025884-

main.pdf?_tid $=371 \mathrm{e} 048 \mathrm{a}-1677-4278-\mathrm{b} 8 \mathrm{db}-$ d04445b82784\&acdnat=1523503652_c0f69e842124e26bc905c028b4f9742b. 


\section{Appendix A}

Sample of Statistical Literacy Test

Do these statements (number 1-4) accurately describe the data in this pie chart?

Informatics Students

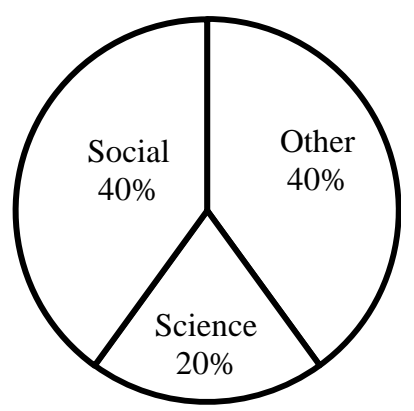

Non-Informatics Students

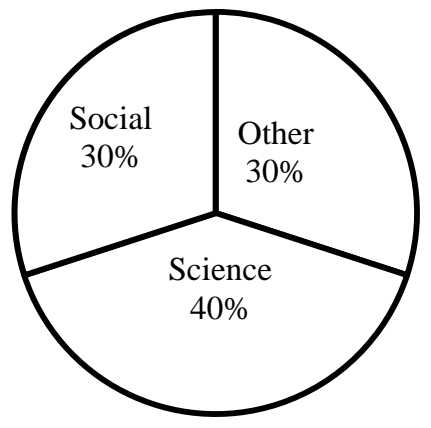

1. Yes No Among students with social science background, $40 \%$ are informatics students.

2. Yes No $40 \%$ of informatics students are students with social science background.

8. True False If stock drops from $\$ 300$ to zero, that is a $300 \%$ decrease.

9. In the previous question (number 15), what is their median salary?
a. $\$ 65,000$
b. $\$ 75,000$
c. $\$ 80,000$
d. $\$ 85,000$

Use this table to answer the questions number 17-18

\begin{tabular}{|l|c|c|c|}
\hline \multirow{2}{*}{ Major } & \multicolumn{2}{|c|}{ Sex } & \multirow{2}{*}{ All } \\
\cline { 2 - 3 } & Male & Female & \\
\hline Informatics & $75 \%$ & $25 \%$ & $100 \%$ \\
\hline Math education & $40 \%$ & $60 \%$ & $100 \%$ \\
\hline Other & $51 \%$ & $49 \%$ & $100 \%$ \\
\hline All & $52 \%$ & $48 \%$ & $100 \%$ \\
\hline
\end{tabular}

10. The following histograms show the number of students receiving each letter grade for two separate physics teachers. Which conclusion about the grades is valid?

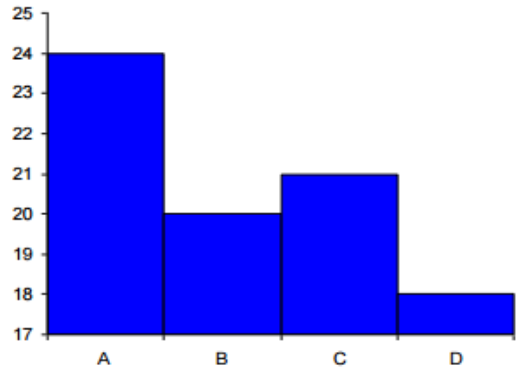

Teacher 1

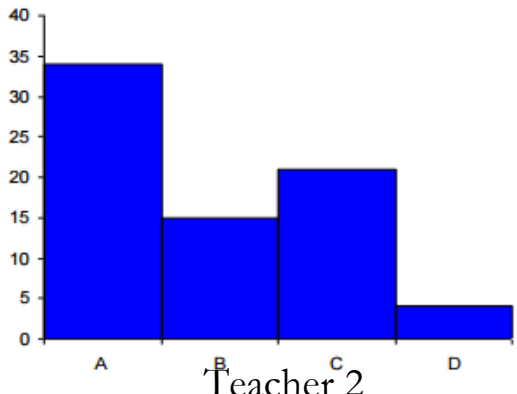

Teacher 2

a. Teacher 1 gave more B's and C's but approximately the same number of A's and D's as Teacher 2

b. Teacher 2 gave more A's and fewer D's than Teacher 1

c. Teacher 2 gave more B's and C's than Teacher 1

d. The overall grade distribution for the two Teachers is approximately equal 


\section{Appendix B}

Mathematics and Statistics Perception Scale (MSPS)

\section{Instructions:}

For each following statements please indicate your agreement or disagreement. You should this by circling the number that most clearly represents your opinion about that statement using the scale below:

$$
\begin{aligned}
& 1=\text { strongly disagree } \\
& 2=\text { disagree } \\
& 3=\text { agree } \\
& 4=\text { strongly agree }
\end{aligned}
$$

\begin{tabular}{clllll}
\hline Number. & \multicolumn{1}{c}{ Item } & \multicolumn{4}{c}{ Agreement/disagreement } \\
\hline 1. & I am confident in my mathematics skills & 1 & 2 & 3 & 4 \\
2. & I enjoy doing calculations & 1 & 2 & 3 & 4 \\
3. & I like using mathematical formula & 1 & 2 & 3 & 4 \\
4. & I understand why we need mathematics in & 1 & 2 & 3 & 4 \\
$\quad$ everyday life & & & & \\
5. & I like college mathematics class & 1 & 2 & 3 & 4 \\
6. & Mathematics is my least favorite subject & 1 & 2 & 3 & 4 \\
7. & I have always loved mathematics & 1 & 2 & 3 & 4 \\
8. & Mathematics comes easy to me & 1 & 2 & 3 & 4 \\
9. & I expect to do well in a statistics course & 1 & 2 & 3 & 4 \\
10. & Statistics is a useful skill in everyday life & 1 & 2 & 3 & 4 \\
11. & Studying mathematics is a waste of time & 1 & 2 & 3 & 4 \\
\hline
\end{tabular}

